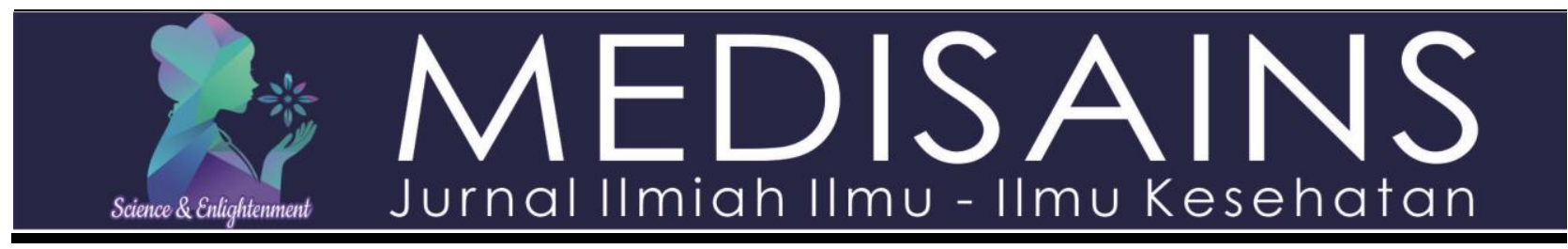

Original Article

\title{
Effectiveness of progressive muscle relaxation and aromatherapy on fatigue in pregnant mothers \\ Tetet Kartilah ${ }^{1}$, Sofia Februanti \\ ${ }^{1}$ Nursing Program Study, Poltekkes Kemenkes Tasikmalaya, Jawa Barat, Indonesia
}

\section{ARTICLE INFORMATION}

Received: January 18, 2020

Revised: March 15, 2020

Available online: April 30, 2020

\section{KEYWORDS}

Pregnancy; Aromatherapy; Pregnant women; Fatigue

\section{CORRESPONDENCE}

Phone: 085222942264

E-mail: sofiafebruanti@gmail.com

\section{A B S T R A C T}

Background: Fatigue in pregnant women can lead to cesarean delivery, also triggering problems during pregnancy, childbirth, and the puerperium. Therefore, there is a need for non-pharmacological interventions to reduce the level of fatigue

Objective: This study aims to determine the effectiveness of giving progressive muscle relaxation (PMR) and aromatherapy to complaints of fatigue in pregnant women

Methods: This is a quasi-experiment with pretest and post-test with control group design. The sampling technique was simple random sampling, consisted of 52 respondents who were divided into two groups. The statistical using a paired $t$-test and independent $t$-test

Results: After the administration of PMR and aromatherapy interventions, the fatigue score decreased significantly from 5.15 to $3.15 ; p<0.001$. In the control group, the fatigue score was reduced from 5.04 to $4.00 ; p<0.0001$. There was a significant difference in fatigue scores in the intervention and control groups $(3.15 \pm 1.592$ vs. $4.00 \pm 0.980 ; p<0.05)$.

Conclusion: Combination progressive muscle relaxation exercises and aromatherapy are effective in reducing fatigue scores in pregnant women.

\section{INTRODUCTION}

Throughout a woman's life cycle, it is natural that she will experience the process of pregnancy, childbirth, and the puerperium. Pregnancy is a gift for every mother. However, pregnancy is considered a stressful experience because it is accompanied by changes in both physical and psychological ${ }^{1}$. Physical and mental changes in pregnant women can be nausea, vomiting, sleep disorders, hormonal changes, which can cause anxiety, depression, symptoms of lack of energy, and fatigue ${ }^{2,3}$. Fatigue is a symptom that is often complained of during pregnancy ${ }^{4}$. Fatigue during pregnancy is a physiological, psychological, and potentially pathological condition from a decrease in energy ${ }^{5}$. This condition can be linked to severe problems for mother and child. The prevalence of fatigue during pregnancy is between $35.4 \%$ to $72 \%{ }^{6-8}$.

Fatigue during pregnancy often occurs, especially during the early trimester and trimester final ${ }^{5,9}$. The cause of-

https://doi.org/10.30595/medisains.v18i1.6421

(2020) by the Medisains Journal. Readers may use this article as long as the work is properly cited, the use is educational and not for profit, and the work is not altered. More information is available at Attribution-NonCommercial 4.0 International. fatigue during pregnancy is still unknown. However, increased hormone levels and stress might be a factor risk ${ }^{10}$. The cause of fatigue during pregnancy is progesterone, which is produced quickly in pregnancy. Tiredness in pregnancy need to be addressed because it can increase the likelihood of birth Section Caesarea (SC), also lead to problems during pregnancy, childbirth, and childbirth, such as spontaneous abortion, preterm labor, rupture of membranes premature ${ }^{1}$.

Fatigue in pregnant women can be overcome in various ways. In Australia, many pregnant women consume herbal medicines to deal with fatigue ${ }^{11}$. Pregnant women who experience fatigue should not consume drugs to overcome fatigue because the drugs used may have side effects in infants ${ }^{12}$. Fatigue in pregnant women should be treated with complementary \& medicine alternative ${ }^{6}$. Non-pharmacological therapy or often referred to as complementary \& alternative medicine, famous and essential in the health field. Complementary \& alternative medicine therapies are medical therapy friends with side effects low ${ }^{13}$. Various 
alternative therapies for complementary \& alternative medicine to deal with complaints of pregnant women include acupuncture, yoga, relaxation, herbal medicine, cognitive-behavioral treatment, etc ${ }^{14-16}$.

Mild to moderate exercise is a complementary \& alternative treatment recommended for pregnant women ${ }^{2}$. During pregnancy, relaxation exercises relieve the tired body and soul of the mother. Pilates and PMR are exercises that can be done to reduce various complaints of pregnant women ${ }^{17}$. Different research results, progressive muscle relaxation can reduce discomfort, pregnancy disorders that often occur, reduce pain in pregnant women with back pain, and can improve the quality of life ${ }^{18}$. Progressive muscle relaxation involves tense the muscle then release the tension. With PMR, mentally and physically, muscle tension can be reduced with progressive muscle relaxation exercises. The provision of relaxation during pregnancy has a substantial effect on embryonic development. Babies born have a higher weight and cry louder ${ }^{17}$.

Another way to reduce complaints in pregnant women is by giving aromatherapy ${ }^{19-21}$. The giving of aromatherapy shows the result of decreasing fatigue ${ }^{20,22}$. Some research results show an increase in relaxation and reduction of fatigue produced by the aroma of essential oils and application through basting to the forearm. Giving aromatherapy significantly improve relaxation and reduce fatigue for the mother in the early post-partum period and received either 23,24 . This study aims to determine the effectiveness of providing PMR and aromatherapy to complaints of fatigue in pregnant women.

\section{METHOD}

\section{Study Design}

This is quasi-experimental with pre and post-test and group control design ${ }^{25}$.

\section{Settings and Respondents}

This study was conducted from February to October 2019 at Kahuripan Health community center Tasikmalaya. The population in this study were all pregnant women. The sampling technique with simple random sampling ${ }^{26}$, totaling 52 people. Criteria for inclusion of patients aged 18-40 years, willing to do PMR and use aromatherapy at least four days/week for two weeks, do not have an allergy to aromatherapy and have no mental disorders

\section{Experimental Procedure}

The intervention group was taught PMR techniques combined with aromatherapy, and it was recommended to apply it for four days/week, whereas the control group was only taught PMR. PMR is muscle relaxation, which is done by applying stress to a group of muscles and stopping the tension while focusing on how the muscles become relaxed. While the administration of aromatherapy is done using the lavender type and given before bed.

\section{The Instrument and Measurement}

This study measures the fatigue score using the Fatigue Rating format (Visual Analog Scale for Fatigue Questionnaire) ${ }^{25}$. This instrument assesses fatigue levels using a numerical rating of $0-10$. A score of 0 means that you don't experience fatigue. Score 1-3 mild fatigue. Score 4-7 moderate fatigue. Score 8-10 severe fatigue. Fatigue scores are measured at the beginning before the intervention, and after two weeks of intervention, both the control group and the intervention group.

\section{Data Analysis}

Data were analyzed through paired t-test and independent t-test because of the data normally distributed ${ }^{27}$.

\section{Ethical Consideration}

This research has passed the test of ethics from the ethics committee of the Ministry of Health polytechnic Tasikmalaya, with registration number 2019/KEPK/PE/IV/00 033.

\section{RESULTS}

The average age of respondents was $29.35 \pm 6.126$ years. The average maternal gestational age was 20.31 \pm 9.108 . Generally, multigravida respondents (78.8\%) (Table 1$)$. Based on table 2, results have the effect of PMR and aromatherapy on reducing fatigue scores in pregnant women $(p<0.05)$. The average fatigue score of pregnant women before PMR and aromatherapy is 5.15, and after are 3.15. This shows that PMR and aromatherapy are effective in reducing fatigue of pregnant women

The results showed that there were differences in fatigue scores of pregnant women in the intervention group and the control group $(p<0.05)$ because the intervention group was given PMR and aromatherapy. In contrast, the control group only received PMR. Therefore the average fatigue score of pregnant women in the intervention group was lower than the control group. The effect size estimation results indicate that PMR and aromatherapy have a substantial and substantive effect on decreasing the fatigue score in pregnant women ${ }^{28}$ (Table 3).

Table 1. Characteristics of respondents $(n=52)$

\begin{tabular}{ll}
\hline Characteristics & Results \\
\hline Age, years (average \pm SD) & $29.35 \pm 6.126$ \\
Gestational age, weeks (average \pm & $20.31 \pm 9,108$ \\
SD) & \\
Gravida & \\
$\quad$ Primigravida & $11(21.2 \%)$ \\
$\quad$ Multigravida & $41(78.8 \%)$ \\
\hline
\end{tabular}


Table 2. The effect of PMR with aromatherapy and PMR only in fatigue scores

\begin{tabular}{lrrrrr}
\multicolumn{1}{c}{ Group } & $\begin{array}{c}\text { Pre } \\
\text { Mean } \pm \text { SD }\end{array}$ & $\begin{array}{c}\text { Post } \\
\text { Mean } \pm \text { SD }\end{array}$ & Mean diff (95\% Cl) & t & p-value \\
\hline PMR and aromatherapy & $5.15 \pm 0881$ & $3.15 \pm 1,592$ & $2,000(1.429$ to 2.571$)$ & 0.704 & 0.0001 \\
PMR (control) & $5.04 \pm 0.528$ & $4.00 \pm 0.980$ & $1.038(0.651-1.426)$ & 0.562 & 0.0001 \\
\hline
\end{tabular}

Paired T-Test

Tabel 3. Differences in fatigue scores after an intervention

\begin{tabular}{lccccc}
\multicolumn{1}{c}{ Group } & Mean \pm SD & Mean diff (95\% Cl) & t & p-value & Effect size \\
\hline PMR and aromatherapy & $3.15 \pm 1.592$ & $0.85(2.51-3.880)$ & 0.039 & 0.026 & 0.64 \\
PMR (control) & $4.00 \pm 0.980$ & & & & \\
\hline
\end{tabular}

Independent T-Test

\section{DISCUSSION}

Table 1 shows the fatigue score of pregnant women before giving progressive muscle relaxation is 5.10 . Fatigue is the most common complaint during pregnancy and post-partum $^{17}$. Pregnancy is characterized by physiological, psychosocial changes, role assumptions, and parental responsibilities. These changes, including fatigue, can affect the quality of life of mothers. Relaxation therapy has recently become an integral part of treatment by reducing anxiety and stress, diverting attention from pain, relieving tension and muscle contractions, facilitating sleep, reducing sensitivity to fatigue, and pain ${ }^{17,29}$. With relaxation, fatigue in pregnant women can be reduced ${ }^{30}$.

PMR is a technique that utilizes a cycle of muscle tension release combined with breathing regulation. In particular, the results of the study showed that the application of the PMR function was effective in reducing the level of fatigue in pregnant women. The reason PMR can provide benefits for the health of pregnant women, he suggested because the main activity of PMR is the relaxation of muscle tension involving sympathetic and parasympathetic nerve fibers. The parasympathetic nervous system dominates the performance of decreasing heart rate, breathing rate, blood pressure, reducing anxiety, and increasing relaxation. This response to relaxation can alleviate pain by reducing tissue oxygen demand, reducing the level of chemicals such as lactic acid, and releasing endorphins. Therefore, reducing anxiety using PMR, results in decreased pain perception, reduces fatigue (fatigue) in pregnant women ${ }^{17}$.

The results of this study indicate that PMR is useful in overcoming fatigue. PMR, which is applied during pregnancy, will make an essential contribution to reducing the level of fatigue of pregnant women so that pregnant women get the comfort and ability to solve problems that may be encountered during pregnancy. PMR during pregnancy is useful for increasing energy and reduces fatigue 31. Relaxation improves the balance between the anterior and posterior hypothalamus, reduces sympathetic activity and catecholamines, reduces muscle tension, reduces blood pressure and heart rate, and regulates breathing. Through PMR, individuals can relax all of their muscles one by one, so they can reduce their anxiety and stress. Relaxation also stops the stress response, such as fatigue $^{8}$.

Aromatherapy is a method known to reduce symptoms of various physiological processes and diseases ${ }^{32}$. Aromatherapy can be used as a complement to other therapies or can even be used as an alternative therapy ${ }^{33}$. The use of aromatherapy has shown the potential to increase relaxation. Lavender is an essential oil that is most often used in research. Several studies have shown that aromatherapy with lavender has anti-inflammatory, antidepressant, hypnotic, sedative, muscle relaxant, anti-bacterial, and anti-spasmodic effects.

The results showed that aromatherapy with lavender oil was effective in reducing pain, fatigue, and pressure and could improve the mood of mother's ${ }^{23}$. Essential oils in aromatherapy treatments increase relaxation when fragrant components stimulate the hypothalamus and activate the nervous parasympatheticsystem ${ }^{34}$. Therefore, increased relaxation and reduced fatigue are produced by the aroma of essential oils and applications through basting to the forearm. Nursing actions in the form of aromatherapy are holistic treatments that are easily given and provide many benefits. Some research results show that the administration of aromatherapy can be an alternative therapeutic option that effectively relieves depressive symptoms, reduces fatigue by providing relaxation to someone ${ }^{35}$.

\section{CONCLUSIONS AND RECOMMENDATION}

PMR and aromatherapy are proven effective in reducing fatigue in pregnant women. Therefore it can be used as an alternative non-pharmacological effort to overcome fatigue in pregnancy.

\section{REFERENCES}

1. Shobeiri F, Manoucheri B, Parsa P, Roshanaei G. Effects of Counselling and Sole Reflexology on Fatigue in Pregnant Women: A Randomized Clinical Trial. J Clin Diagn Res. 2017;11(6):QC01QC04.

2. O'Connor PJ, Poudevigne MS, Johnson KE, Araujo 
JB de, Ward-Ritacco CL. Effects of resistance training on fatigue-related domains of quality of life and mood during pregnancy: A randomized trial in pregnant women with back pain. Psychosom Med. 2018;80(3):327-332.

3. Mamta A, Sonia P, Sheetal K. Effect of Inspiratory Muscle Training and Diaphragmatic Breathing Exercises on Dyspnea, Pulmonary Functions, Fatigue and Functional Capacity in Pregnancy during Third Trimester. J Clin Diagnostic Res. 2019;13(8):1-4.

4. Cappuccio FP, Miller MA, W. Lockley S, Rajaratnam SMW. Sleep, Health, and Society from Aetiology to Public Health. 2nd editio. United Kingdom: Oxford university press; 2018.

5. Bossuah, Atsor K. Fatigue in Pregnancy. Int $J$ Childbirth Educ J. 2017;32(1):p10-12. 3p.

6. Lauche R, Hall H, Adams J, Steel A, Broom A, Sibbritt $D$. Health-care utilisation amongst pregnant women who experience sleeping problems and/or tiredness or fatigue: secondary analysis of a crosssectional survey of 1835 pregnant women. Sleep Breath. 2016;20(1):355-362.

7. Miok K, Younglan K. The mediating effect of fatigue on the relationship between pregnancy stress and depression during the Third Trimester of Pregnancy. J East-West Nurs Res. 2018;24(1):8189.

8. Mahmoudirad G, Hosseini $M$, Nasirizade $M$, Biabani F. The Effects of Benson's Relaxation Response on Fatigue During Pregnancy: A TwoGroup Randomized Controlled Field Trial. Mod Care J. 2017;14(3):1-5. http://mcjbums.com/articles/66965.html.

9. Cheng C, Chou Y, Wang P, Tsai J, Liou S. Survey of trend and factors in perinatal maternal fatigue. Nurs Health Sci. 2015;17(1):64-70.

10. Bai G, Korfage IJ, Groen EH, Jaddoe VW V, Mautner E, Raat H. Associations between Nausea , Vomiting, Fatigue and Health-Related Quality of Life of Women in Early Pregnancy : The Generation R Study. PLoS One. 2016;11(11):1-14. doi:10.1371/journal.pone.0166133

11. MClinSc JF, Adams J, Steel A, Broom A, Gallois C, Sibbritt D. Women's Use and Self-Prescription of Herbal Medicine during Pregnancy: An Examination of 1,835 Pregnant Women. Women's Heal Issues. 2015;25(4):396-402.

12. Nazik E, Eryilmaz G. Incidence of pregnancyrelated discomforts and management approaches to relieve them among pregnant women. J Clin Nurs. 2014;23(11):1736-1750.

13. Hasbi H Al, Chayati N, Makiyah SNN. Progressive muscle relaxation to reduces chronic pain in hemodialysis patient. medisains, J IIm ilmu-ilmu Kesehat. 2019;3(2019):62-66.

14. Bacaro V, Benz F, Pappaccoglia A, et al. Interventions for sleep problems during pregnancy: A systematic review. Sleep Med Rev. 2019;50(12):1-17.

15. Tomfohr-Madsen LM, Clayborne ZM, Rouleau CR, Campbell TS. Sleeping for Two: An Open-Pilot Study of Cognitive Behavioral Therapy for Insomnia in Pregnancy. Behav Sleep Med. 2017;15(5):377-393.
16. Mohammadi F, Malakooti J, Jalil Babapoor heiroddin, Mohammad-Alizadeh-Charandabi S. The effect of a home-based exercise intervention on postnatal depression and fatigue: A randomized controlled trial. Int J Nurs Pract. 2015;21(5):478485.

17. Muller A, Hammill H V, Hermann C. The Effects of Pilates and Progressive Muscle Relaxation Therapy on Maternal Stress and Anxiety: a Literature Review. Int $J$ Humanit Soc Sci. 2016;6(6):195-203.

18. Sadeghi A, Sirati-Nir M, Ebadi A, Aliasgari M, Hajiamini Z. The effect of progressive muscle relaxation on pregnant women's general health. Iran J Nurs Midwifery Res. 2015;20(6):655-660.

19. Shirazi M, Mohebitabar S, Bioos S, et al. The Effect of Topical Rosa damascena (Rose) Oil on Pregnancy-Related Low Back Pain: A Randomized Controlled Clinical Trial. J Evid Based Complementary Altern Med. 2017;22(1):120-126. doi:10.1177/2156587216654601

20. Effati-Daryani, F., Mohammad-AlizadehCharandabi, S., Mirghafourvand, M., Taghizadeh, M., Bekhradi, R., \& Zarei S. Effect of Lavender cream with or without footbath on sleep quality and fatigue in pregna ncy and postpartum: a randomized controlled trial. Women Health. 2018;58(10):1-13.

21. Conrad P. Women's Health Aromatherapy a Clinically Evidence-Based Guide for Nurses, Midwifes, Doulas, and Therapists. London and Philadelphia: Singing dragon; 2019.

22. Ahmady S, Rezaei M, Khatony A. Comparing effects of aromatherapy with lavender essential oil and orange essential oil on fatigue of hemodialysis patients: A randomized trial. Pract Complement Ther Clin. 2019;36(5):64-68.

23. Asazawa K, Kato $Y$, Yamaguchi A, Inoue A. The Effect of Aromatherapy Treatment on Fatigue and Relaxation for Mothers during the Early Puerperal Period in Japan: A Pilot Study. Int $J$ Community Based Nurs Midwifery. 2017;5(4):365-375.

24. Rezaie-Keikhaie K, Hastings-Tolsma M, Bouya S, et al. Effect of aromatherapy on post-partum complications: A systematic review. Complement Ther Clin Pract. 2019;35(3):290-295.

25. Ingham-broomfield B. A nurses ' guide to Quantitative Research. Aust $J$ Adv Nurs. 2015;32(2):32-38.

26. Polit DF, Hungler BP. .Essentials of Nursing Research: Methods, Appraisal, and Utilization. (8th Editi. Philadelphia: Wolters Kluwer/Lippincott Williams and Wilk; 2013.

27. Dahlan S. Statistik Untuk Kedokteran Dan Kesehatan: Deskriptif, Bivariat, Dan Multivariat. 6th ed. Jakarta: Salemba Medika; 2019.

28. Correll J, Mellinger C, Mcclelland GH, Judd CM. Avoid Cohen 's "Small" , "Medium ", and "Large " for Power Analysis. Trends Cogn Sci. 2019;24(3):200-207.

doi:10.1016/j.tics.2019.12.009

29. Gökşin I, Ayaz-Alkaya S. The effectiveness of progressive muscle relaxation on the postpartum quality of life. Asian Nurs Res (Korean Soc Nurs Sci). 2018;12(2):86-90. 
doi:10.1016/j.anr.2018.03.003

30. Haakstad LAH, Torset $B, \varnothing K$. What is the effect of regular group exercise on maternal psychological outcomes and common pregnancy complaints? An assessor blinded RCT. Midwifery. 2016;32(10):8186.

31. Ward-Ritacco C, Poudevigne MS, O'Connor PJ. Muscle strengthening exercises during pregnancy are associated with increased energy and reduced fatigue. J Psychosom Obstet Gynecol. 2016;37(2).

32. K. Rezaie-Keikhaiea et al. , "Effect of aromatherapy on post-partum complications: A systematic review," Complement. Ther Clin Pr. 2019;35:290295.

33. Kianpour M, Moshirenia F, Kheirabadi G, Asghari $G$, Dehghani A, Dehghani-tafti A. The Effects of
Inhalation Aromatherapy with Rose and Lavender at Week 38 and Postpartum Period on Postpartum Depression in High-risk Women Referred to Selected Health Centers of Yazd, Iran in 2015. Iran J Nurs Midwifery Res. 2018;23(5):395-401.

34. Asazawa K, Kato Y, Yamaguchi A, Inoue A. The Effect of Aromatherapy Treatment on Fatigue and Relaxation for Mothers during the Early Puerperal Period in Japan: A Pilot Study. Int $J$ Community Based Nurs Midwifery. 2017;5(4):365-375.

35. Asazawa K, Kato Y, Koinuma R, Takemoto N, Tsutsui S. Effectiveness of Aromatherapy Treatment in Alleviating Fatigue and Promoting Relaxation of Mothers during the Early Postpartum Period. Open J Nurs. 2018;8(3):196-209. 